\title{
VOCES Y OTREDAD. \\ DE LAS CARTAS DESDE MI CELDA A BÉCQUER Y LAS BRUJAS
}

\author{
VOICES AND OTHERNESS. \\ FROM THE LETTERS DESDE MI CELDA TO BÉCQUER Y LAS BRUJAS
}

\author{
Miriam LÓPEZ SANTOS \\ Universidad de León \\ mlops@unileon.es
}

\begin{abstract}
Resumen: La crítica especializada ha relacionado las leyendas de las cartas Desde mi celda de Bécquer con la insistencia por parte del autor en la búsqueda y recuperación del folclore y de las tradiciones populares. No obstante, el acercamiento a las mismas exige una doble lectura. La riqueza polifónica muestra que, al Bécquer folclorista, habría de añadírsele su faceta de lector afamado, imprescindible en su configuración como narrador de historias. El escritor sevillano mira al pueblo, recoge y bebe de la tradición, pero la filtra a través del prisma del movimiento gótico, de los ecos que aún permanecían en la literatura y que se atisbaban en las últimas manifestaciones de las narraciones románticas y en la incipiente narrativa realista. El largometraje recientemente estrenado Bécquer y las brujas ahonda en esta riqueza polifónica de una figura, construida desde la más pura otredad: la de la bruja.
\end{abstract}

Palabras clave: Bécquer. Desde mi celda. Bécquer y las brujas. Brujas. Polifonía. Gótico. Otredad.

\begin{abstract}
Literary scholarship has credited the legends collected in Bécquer's letters Desde mi celda for the writer's interest in the research and recovery of folklore and popular traditions. However, when approaching these traditional stories, another perspective is possible: Bécquer's polyphonic narrations are rooted in his wide readings, from which he draws the material of his stories. The Sevillian writer observes and grasps the people's cultural traditions, but through the filter of the Gothic, the echoes of the last romantic prose and the emerging realist narrative. The newly released film Bécquer y las brujas highlights the richness of his compositions, based on the purest otherness: the figure of the witch.
\end{abstract}

Keywords: Bécquer. Desde mi celda. Bécquer y las brujas. Witches. Polyphonic. Gothic. Otherness. 


\section{POLIFONÍA Y OTREDAD EN LA CARTA VI DESDE MI CELDA}

Toda relectura del Bécquer narrador de leyendas, del Bécquer Desde la celda, descubre la complejidad de un discurso extremadamente rico en interpretaciones, que se asientan en sus diversas facetas de escritor: la del folclorista, que recoge la tradición de un pueblo en la senda de los románticos europeos (Benítez, 1971; Rubio Jiménez, 2002; Díez de Revenga, 2007-2008); la del poeta, que nutre de lirismo las narraciones (Sebold, 1989; Estruch, 2020); la del periodista-historiador, corresponsal de El Contemporáneo, y sus exigencias continuas de veracidad (Palomo, 1985; Domínguez Lasierra, 1999; Estruch, 2020); pero también la del lector avezado y afanoso, que es capaz de condensar entre sus páginas toda una tradición de literatura de brujas, desde La Tempestad y Macbeth a La Celestina, e insertarse, al propio tiempo, en la corriente de herederos de la novela gótica, que deja intensos ecos en el texto, más allá de un ambiente legendario, hostil y ruinoso (Rubio Jiménez, 2002), como comprobaremos más adelante.

Estas facetas se superponen, se enriquecen, se nutren unas de las otras y condicionan el tratamiento de un tema, el de la brujería, que acaba de conocer una nueva revisión en el documental Bécquer y las brujas de Susana $\mathrm{Cid}^{1}$. La historia, que se centra en la Carta VI que Gustavo Adolfo Bécquer escribiera en el monasterio de Veruela, a los pies del Moncayo, ya muy enfermo de tuberculosis, en 1864, fusiona leyenda, lecturas, historia y biografía. Supone una aproximación al mundo de las brujas, pero también a las profundidades del alma convulsa del poeta, para descubrir y defender una arista nueva en su concepto de otredad, marcado por la polifonía enunciativa, en términos de Ducrot (1984: 200-214).

Adentrarse en esta nueva visión de Susana Cid supone, en efecto, comprender la polifonía primigenia que enmarca el discurso becqueriano (Díez de Revenga, 2007-2008: 370 ), y que ya había sido trabajado en sus leyendas, consiguiendo un acercamiento a la figura de la bruja profundo y extenso, marcado por la pluriperspectiva, que se hace extensible al lector, con el que se produce un juego continuado, y casi perverso, de tensiones y distensiones. La compleja relación de puntos de vista, complementarios, semejantes, e incluso, enfrentados en la mirada de Bécquer a la bruja Casca y a toda la estirpe de brujas de Trasmoz, el pueblo maldito y excomulgado, más que vincularse a la esencia de la leyenda como subgénero narrativo (Díez de Revenga, 2007-2008), hunde sus raíces en el conflicto irracionalidad-racionalismo, responsable del nacimiento de la novela gótica inglesa (López Santos, 2020: 67-68). En el siglo racionalista por excelencia,

\footnotetext{
${ }^{1}$ El documental Bécquer y las brujas de 2018 ha sido galardonado con cuatro premios Simón del cine aragonés en 2019 y con el Premio Augusto Aragonés Visiones de la Historia en el $24^{\circ}$ Festival de Cine de Zaragoza, así como con Premio al Mejor Documental en el Festival Internacional de Cine de Nunes (Barcelona) y la Mención Especial del Jurado Joven en el Festival de Cine de Madrid. Igualmente, cabe destacar las ocho candidaturas a los Goya en 2019: mejor película, mejor dirección novel, mejor guion original, mejor música original, mejor dirección de fotografía, mejor montaje, mejor película documental y mejor sonido.
} 
en el que el mundo, y por extensión la literatura, se mueve en una confusa dualidad, la aparición de todo elemento sobrenatural tendría dos posibles explicaciones. Aquella que, por una parte, decanta el fenómeno del lado de la razón, negando su existencia y la que, por otra, reconoce y admite, trasgrediendo los límites de este racionalismo imperante, la verdad de determinados fenómenos inexplicables. La omnisciencia narrativa gótica da voz a dos anunciadores: del lado de la razón se posicionan los señores, rechazando toda postura irracional, por entenderla como ancestral e ilógica; postura esta que pasan a patrocinar los criados, que se presentan como crédulos e ignorantes, abandonados a todo tipo de fantasías o maldiciones.

Este discurso antitético se hace extensible al lector, al que se le reclama una actitud cooperativa (Fernández, 2018: 90) desde el inicio del relato de los acontecimientos, haciéndole partícipe de la historia y condicionando, a medida que avanza dicho relato, su sentencia. El lector se convierte, de esta manera, en "la instancia de mediación creadora por excelencia”, concepto reelaborado por Pura Fernández a partir de la expresión de Philippe Hamon (2007: 30). La historia precisa de una voz indispensable y última, la que aporta el lector, que, a través del componente subjetivo del acto lector, dota de existencia a una imagen "a partir de un proceso de percepción visual y de elaboración mental que sitúa la mirada en unas coordenadas socio-culturales específicas” (Fernández, 2020: 91).

El lector gótico, esencialmente femenino, entrenado en la novela sentimental, y que buscaba una respuesta sensible y basada preminentemente en el efectismo, es reemplazado en el escritor sevillano por un público amplio, erudito e ilustrado, "el lector de un periódico conservador liberal" (Escruch, 2020) de la capital, El Contemporáneo. El proceso de percepción visual exige multiplicar los mecanismos para atrapar a un lector más exigente, en tanto que domina en él la desconfianza y el escepticismo. Bécquer lo sabe y es por ello por lo que se enmascara en otras voces, todas bajo la forma del narrador testigo que habría de tomar, indudablemente, del maestro Poe. Y, aunque, como sostiene Roas (2011: 125), "Bécquer nunca mencionó, a pesar de las afirmaciones de Rodríguez Guerrero-Strachan (1999: 79-80), el nombre de Edgar Allan Poe ni en sus relatos ni en sus textos críticos", estas leyendas se sitúan ciertamente en la línea del de Boston sobre todo en lo que "se refiere al tratamiento realista de lo sobrenatural y lo macabro" (Roas: 2011: 125), al emplazamiento de la narración en el tiempo presente y al manejo del suspense narrativo; condicionantes estos más que evidenciables de la lectura del texto. Desde mi celda se inserta en esta tradición que busca un lector cómplice, juguete de las voces contrapuestas que crean el discurso.

La carta IV se abre con este narrador-paseante en primera persona, tomando un discurso incrédulo. Dirige sus palabras al público, ahora bajo la máscara del periodistahistoriador "que procede un mundo civilizado" (Díez de Revenga, 2007-2008: 372), al que pretende atrapar en la veracidad de lo narrado y, tras cerciorarse de existencia de pruebas perfectamente constatables: 
Queridos amigos: Hará cosa de dos o tres años, tal vez leerían ustedes en los periódicos de Zaragoza la relación de un crimen que tuvo lugar en uno de los pueblecillos de estos contornos. Tratábase del asesinato de una pobre vieja a quien sus convecinos acusaban de bruja. Últimamente, y por una coincidencia extraña, he tenido ocasión de conocer los detalles y la historia circunstanciada de un hecho que se comprende apenas en mitad de un siglo tan despreocupado como el nuestro (Bécquer, 2019: 231).

Su relato, sin embargo, viene marcado por la ironía, trasunto del discurso del propio poeta, pues "al representar (Amores, 1999: 193) el escepticismo propio del mundo civilizado, debe enmascararlo para ganarse la confianza del hombre del pueblo". La ironía, que supone al mismo tiempo, orientaciones discursivas opuestas o centros de perspectiva, difíciles de definir (y a veces también de percibir) de manera precisa (Ducrot, 1984: 208-214) facilita la ocultación de este discurso escéptico, engañando al enunciador crédulo (Bruzos, 2005: 42), el pastor, y con la mirada puesta, en último término, en el lector, al que ya ha atrapado y a través del cual procederá a manejar empleando todos los mecanismos del terror que, a través de Edgar Allan Poe, le ofrece el gótico:

¡A ver, a ver! Cuénteme usted cómo pasó eso, porque debe ser curioso -añadí, mostrando toda la credulidad y el asombro suficiente para que el buen hombre no maliciase que sólo quería distraerme un rato oyendo sus sandeces; pues es de advertir que hasta que no me refirió los pormenores del suceso no hice memoria de que, en efecto, yo había leído en los periódicos de provincia una cosa semejante.

El pastor, convencido por las muestras de interés con que me disponía a escuchar su relato de que yo no era uno de esos señores de la ciudad dispuesto a tratar de majaderías su historia, levantó la mano en dirección a uno de los picachos de la cumbre, y comenzó así, señalándome una de las rocas que se destacaba oscura e imponente sobre el fondo gris del cielo, que el sol, al ponerse tras las nubes, teñía de algunos cambiantes rojizos (Bécquer, 2019: 235).

El lector, ya alterado y confuso, decantará su postura de un lado de la balanza de la razón, gracias a esta insistencia en la veracidad de los hechos, desde un refinado planteamiento histórico; o del otro lado, a través de la técnica narrativa del suspense y de todo un entramado efectista en el dibujo de la atmósfera, que modela los tiempos y produce el efecto del miedo, en sus dos vertientes: terror y horror (Zavala, 1995: 120125; López Santos, 2020: 72-74). Tras esta manifiesta incredulidad y en la voz irónica desdoblada, se alza el Bécquer lector de literatura gótica, alejado de toda corriente folclórica, que presenta un escenario perfectamente propicio para que las grietas de la realidad expulsen a su elemento sobrenatural.

El paisaje sublimemente gótico se manifiesta complejo y ambiguo. Es un elemento estructural cuya finalidad no se reduce a ser el ámbito en el que se desarrolla la acción, sino que ayuda a configurar los rasgos psicológicos del personaje e influye en sus conductas, llegando incluso a condicionar su zozobra final. La subida al castillo de Trasmoz viene determinada por la intersección de una serie de elementos imprescindibles, sin los cuales sería imposible que se produjera el efecto del terror, el manejo del suspense. Son estos ecos indiscutibles de regusto gótico, inmensidad, infinidad, oscuridad, soledad 
o brusquedad, como elementos constitutivos de lo sublime (Kant, 1985: 13-14; Burke, 2005: 86-87), los que contribuirán a abrir las puertas de lo posible a la historia de la bruja Casca:
Ya estaba para acabar el día. El cielo, que desde el amanecer se mantuvo cubierto y nebuloso, comenzaba a ensombrecerse a medida que el sol, que antes transparentaba su luz a través de las nieblas, iba debilitándose, cuando, con la esperanza de ver su famoso castillo como término y remate de mi artística expedición, dejé a Litago para encaminarme a Trasmoz, pueblo del que me separaba una distancia de tres cuartos de hora por el camino más corto. Como de costumbre, y exponiéndome, a trueque de examinar a mi gusto los parajes más ásperos y accidentados, a las fatigas y la incomodidad de perder el camino por entre aquellas zarzas y peñascales, tomé el más difícil, el más dudoso y más largo, y lo perdí, en efecto, a pesar de las minuciosas instrucciones de que me pertreché a la salida del lugar.
Ya enzarzado en lo más espeso y fragoso del monte, llevando del diestro la caballería por entre sendas casi impracticables, ora por las cumbres para descubrir la salida del laberinto, ora por las honduras con la idea de cortar terreno, anduve vagando al azar un buen espacio de tarde, hasta que, por último, en el fondo de una cortadura tropecé a un pastor, el cual abrevaba su ganado en el riachuelo, que, después de deslizarse sobre un cauce de piedras de mil colores, salta y se retuerce allí con un ruido particular que se oye a gran distancia, en medio del profundo silencio de la Naturaleza, que en aquel punto y a aquella hora parece muda o dormida (Bécquer, 2019: 232).

Bécquer no solo pretende facilitar al lector la labor de percepción de los acontecimientos de la historia, intentando hacerle partícipe de la magnificencia y sublimidad del espacio, sino que procura moverle, desestabilizar sus principios racionales asentados en el rechazo a cualquier condicionante supersticioso. Por ello, y como teorizara Kant (1984: 13-14), todo el escenario y cada una de sus partes, en consonancia con esa estética del exceso que patrocina el relato y, que fue calificada como espacio terrorífico, se pone al servicio del lector el único propósito de generar el miedo:

Cuando el pastor terminó su relato llegábamos precisamente a la cumbre más cercana al pueblo, desde donde se ofreció a mi vista el castillo oscuro e imponente, con su alta torre del homenaje, de la que sólo queda en pie un lienzo de muro con dos saeteras que transparentaban la luz y parecían los ojos de un fantasma. En aquel castillo, que tiene por cimiento la pizarra negra de que está formado el monte, y cuyas vetustas murallas, hechas de pedruscos enormes, parecen obra de titanes, es fama que las brujas de los contornos tienen sus nocturnos conciliábulos.

La noche había cerrado ya, sombría y nebulosa. La luna se dejaba ver a intervalos por entre los jirones de las nubes que volaban en derredor nuestro, rozando casi con la tierra, y las campanas de Trasmoz dejaban oír lentamente el toque de oraciones, como al final de la horrible historia que me acababan de referir (Bécquer, 2019: 241).

Este castillo gótico en ruinas tiene su correspondencia exacta en la imagen mental asimilada a partir de múltiples lecturas góticas, por lo que se mostraría perfectamente identificable para este público de mediados del siglo XIX (López Santos, 2010: 59). Sería este el mismo público que según Larra dejaba en las estanterías los clásicos para leer la 
Galería Fúnebre ${ }^{2}$ de Agustín Pérez Zaragoza; un público que asume los mecanismos sensoriales y se deja imbuir por la atmósfera gótica (recreada en sus leyendas más alabadas y en las cartas que precedieron a esta en el propio periódico).

Dicha atmósfera, a pesar de presentarse ante el lector como un mundo aparentemente finito, se descubre en el relato como arquitectura inagotable. No hay descanso, el personaje y, de la mano de este, el lector, apenas si puede tomar aliento y continuar con la lectura. La escenografía se adueña del discurso, se apodera de todas las voces y asume los momentos de mayor suspense y tensión narrativa, impulsando en el lector lo que Pura Fernández (2018: 91) denomina, siguiendo a Fabra Soldevila en Filosofía de la Legislación Natural fundada en la Antropología (1838), "el nervio gran simpático, que prepara para la acción y se activa en las situaciones de peligro y de estrés". Cuando todo ha quedado velado por una intensa niebla, una niebla, metonimia de la confusión del personaje, que lo envuelve todo en una oscuridad espeluznante, fría, casi apocalíptica, aparece "una sensación de penoso malestar que vulgarmente podría llamarse preludio del miedo".

Así se genera en el relato esta serie de emociones, todas ellas derivadas del concepto freudiano de Unheimlich, pero en la interpretación acertada de Mark Fisher (2018: 12), no únicamente como lo siniestro o lo ominoso, sino como todo lo que implica no sentirse en casa. Al retornar a Veruela, espacio que tampoco se aprecia como propio, sí, en cambio como perturbador e inquietante (así lo constata en otras de sus castas), le estremece profundamente el recuerdo de lo narrado:

Ahora que estoy en mi celda, tranquilo, escribiendo para ustedes la relación de estas impresiones extrañas, no puedo menos de maravillarme y dolerme de que las viejas supersticiones tengan todavía tan hondas raíces entre las gentes de las aldeas, que den lugar a sucesos semejantes; pero ¿por qué no he de confesarlo?, sonándome aún las últimas palabras de aquella temerosa relación; teniendo junto a mí a aquel hombre que tan de buena fe imploraba la protección divina para llevar a cabo crímenes espantosos; viendo a mis pies el abismo negro y profundo en donde se revolvía el agua entre las tinieblas, imitando gemidos y lamentos, y en lontananza el castillo tradicional, coronado de almenas oscuras, que parecían fantasmas asomadas a los muros, sentí una impresión angustiosa, mis cabellos se erizaron involuntariamente y la razón, dominada por la fantasía, a la que todo ayudaba, el sitio, la hora y el silencio de la noche, vaciló un punto y casi creí que las absurdas consejas de las brujerías y los maleficios pudieran ser posibles (Bécquer, 2019: 241).

\footnotetext{
${ }^{2}$ Lector asiduo en su empeño de "escribir para mi público y sin saber quién es el público" (Larra, 1981: 128), fue uno de los primeros en pronunciarse en contra del gusto por lo gótico. La nueva moda gótica llegada desde Francia, no era sino un síntoma más del estado de pobreza intelectual que dominaba las letras españolas que, ante la falta de producción nacional o precisamente por ella, se veía obligada a acudir a literaturas foráneas en busca de lecturas. Larra se refiere a esta tendencia del público en aquella cuestión, ¿Será el público el que compra la Galería Fúnebre de espectros y sombras ensangrentadas, y las poesías de Salas [Francisco Gregorio Salas], o el que deja en las librerías las Vidas de los españoles célebres y la traducción de la Ilíada? (Larra, 1981: 135).
} 
Se distancia esta postura de la defendida por Sebold (1989: 21), que ve en dicho planteamiento la finalidad única de la verosimilitud, dentro de su concepción de lo fantástico. Roas (2011: 127) sostiene la postura contraria al considerar que es el tono sublime y el efecto terrorífico que genera el que nos hace olvidar que nos encontramos ante una leyenda, enalteciendo la emoción del miedo como propósito definitivo.

El Bécquer lector ávido cede su voz a la postura patrocinada por el aldeano, epítome de la credulidad de un pueblo y representación primera, junto a la criada, de la vertiente irracionalista. Este recoge ahora la voz del Bécquer folclorista, quien, a la manera de un viajero inglés del siglo XVIII, y desde un marcado distanciamiento de la acción, observa la realidad desde la más pura otredad, marcando una declarada posición de superioridad frente al oscurantismo. Queda detallada toda su galería de tópicos más populares a través de la historia de la bruja Casca, empleando la pluriperspectiva con la intención última de proporcionar mayor credibilidad a lo narrado, al tiempo que mantiene la tensión del discurso gracias a las sucesivas interrupciones que dirigen la atención al lector. Es el aldeano, pero es el pueblo, como la voz intertextual que entronca con toda la tradición de la literatura de brujas que tiene en el Malleus Maleficarum (1486) el documento origen, la que se alza "para golpear a las brujas y sus herejías con poderosa maza, en tanto que fusiona la figura de la bruja con "la servidumbre al diablo, la mujer que vuela y que comente crímenes y la sociedad secreta que celebra reuniones" (Lara Alberola, 2018: 42).

Casca, verdadera bruja o una víctima más de la mentalidad de una comunidad anclada en tiempos de inquisición y oscuridad, según la voz en la que incida el punto de vista, aparece descrita, desde el estereotipo, entre bruja y hechicera, según la clasificación de Eva Lara Alberola (2019: 40). A la Tía Casca, "alta, seca, haraposa, con greñas blancuzcas y cuerpo corvo" (Bécquer, 2019: 236), se enfrenta, para darle muerte, un colectivo formado únicamente por "voces varoniles" (Bécquer, 2019: 236), que parecieran que persiguen a "un lobo" (Bécquer, 2019: 236), respondiendo a la imaginería propia del Maleficarum que vincula a la mujer, frente al dominio absoluto del pensamiento masculino, con la naturaleza, por la posibilidad de metamorfosis ante el contacto intenso y continuado con la misma, por la dominación que hace de ella, al teñir de rojo el cielo y cubrirlo de nieblas y por el conjuro de protección que pronuncia. La voz colectiva la presupone, al propio tiempo, como desafiante de la figura de Dios y adoradora del diablo, y aunque implora perdón y se encomienda a Dios y a los santos, solo consigue ser acusada de blasfemia, incluso de hablar en otras lenguas o rezar al revés, por lo que, a los mitos y leyendas vinculados a las brujas, añadimos la demonolatría, en terminología de Caro Baroja (1966).

Bécquer emplea también, como artificios responsables de la tensión narrativa, la acusación por parte de los aldeanos de maleficios como "el unto con el que frotan su cuerpo para poder volar o el mal de ojo a reses y personas" (Bécquer, 2019: 241), como registra Montserrat Amores (1999: 195), el encantamiento del pueblo, el envenenamiento de las aguas. La escena es deliberadamente teatral, buscando siempre al lector, que se estremece con el final del relato, el que recoge la aterradora muerte de Casca: 
[...] abalanzándose a sus perseguidores, fuera de sí, con las greñas sueltas, los ojos inyectados en sangre y la hedionda boca entreabierta y llena de espuma, cuando la oí arrojar un alarido espantoso, llevarse por dos o tres veces las manos al costado con grande precipitación, mirárselas y volvérselas a mirar maquinalmente, $\mathrm{y}$, por último, dando tres o cuatro pasos vacilantes, como si estuviese borracha, la vimos caer al derrumbadero. [...] La vieja de Lucifer tenía siete vidas como los gatos. Cayó por el derrumbadero donde a cualquiera otro que se le resbalase un pie no pararía hasta lo más hondo, [...] pero ella, con el ansia de la muerte y sin cesar de proferir, ora horribles blasfemias, ora palabras santas mezcladas de maldiciones, se enroscaba en derredor de los matorrales. Sus dedos largos, huesosos y sangrientos se agarraban como tenazas a las hendiduras de las rocas, de modo que, ayudándose de las rodillas, de los dientes, de los pies y de las manos, quizás hubiese conseguido subir hasta el borde si algunos de los que la contemplaban, y que llegaron a temerlo así, no hubiesen levantado en alto una piedra gruesa, con la que le dieron tal cantazo en el pecho, que piedra y bruja bajaron a la vez saltando de escalón en escalón por entre aquellas puntas calcáreas, afiladas como cuchillos, hasta dar, por último, en ese arroyo que se ve en lo más profundo del valle.

Una vez allí, la bruja permaneció un largo rato inmóvil, con la cara hundida entre el légamo y el fango del arroyo, que corría enrojecido con la sangre; después, poco a poco, comenzó como a volver en sí y a agitarse convulsivamente. [...]

Así estuvo algún tiempo, removiéndose y queriendo inútilmente sacar la cabeza fuera de la corriente, buscando un poco de aire, hasta que, al fin, se desplomó muerta, muerta del todo, pues los que la habíamos visto caer (Bécquer, 2019: 239-241).

La voz narradora considera que el linchamiento es un crimen espantoso. Sin embargo, ha asistido al relato de los hechos de manera un tanto distante y ha favorecido que el personaje de la Tía Casca se construya desde una absoluta alteridad, incidiendo en los estímulos que van a provocar las emociones buscadas en el lector: el físico degradado, los elementos que la acompañan, la terrorífica y sobrecogedora muerte final y las sensaciones que genera en los vecinos de Trasmoz. Estos artificios se completan gracias a la voz de la muchacha que sirve en el convento, que, como el aldeano, representa a la voz colectiva. Su punto de vista confirma una vez más el apego a las tradiciones más ancestrales y terribles del pueblo, detallando todo el repertorio de supersticiones para impedir la visita de las brujas, vivas o muertas:

Después de las doce de la noche, pues las brujas que lo quisieran impedir no tienen poder sino desde las ocho hasta esa hora, se toma el cedazo, se hacen sobre él tres cruces con la mano izquierda y, suspendiéndole en el aire, cogido por el aro con las puntijeras, se le pregunta. Si se ha olvidado alguna palabra del Credo, da vueltas por sí solo, y si no, se está quietico, quietico, como la hoja en el árbol cuando no se mueve una paja de aire (Bécquer, 2019: 244).

Tras esta intervención, solo resta escuchar al último narrador, que enlaza con el primero, trasunto del Bécquer ilustrado, historiador y periodista. No obstante, la multiplicidad de voces ha afectado a su posición final y, como en todo relato fantástico que se asienta en el resquebrajamiento de nuestra realidad cotidiana (Roas 2001: 8), el efecto emocional intenso al que ha asistido, marcado por la turbación, la incredulidad, la 
inquietud, el desasosiego, el horror, pero también por la compasión, modifica su percepción de lo real y deja el camino abierto a la última de las voces, que es quizás la primera, por imprescindible, siempre intuida aunque, en ocasiones, directamente señalada, la voz del lector, que se asoma a la historia y recorre, junto a cada uno de las voces la leyenda de la Tía Casca. Debe, pues, retornar al comienzo, caminar lo caminado y reconstruir el relato una vez más, a partir de sus propias emociones.

\section{NUEVAS VOCES PARA NUEVOS DISCURSOS}

El testigo de esta voz lo toma Elena Cid a través de la joven poeta Laura Contreras, que atrapada por la historia y buscando respuestas a lo sentido y vivido, decide viajar a Veruela tras los pasos de la Tía Casca y de Gustavo Adolfo Bécquer. La novedad reside en el hecho de que, asumida la interpretación tras la lectura, su experiencia en el pueblo de Trasmoz generará otra voz diferente para la polifonía del texto. Este es el motivo por el cual, por encima de la valiosa revisión histórico literaria de la brujería y del propio Bécquer, nos interesa la recreación del nuevo punto de vista. El fragmentarismo afectará a la composición de la ficción, que no se construye de forma lineal ni entrelazada, sino que avanza a través de diversos fotogramas que se justifican en las palabras del propio texto y en las aportaciones de escritores, teóricos, críticos literarios e historiadores.

Bécquer y las brujas comienza con los ojos perdidos de Laura, intentando escribir sin aparente éxito unos versos, ante una más que notoria falta de inspiración, en la silenciosa e imponente Biblioteca Nacional, hasta que se topa con la obra de Bécquer Desde mi celda. Mientras suenan en off las palabras del propio autor, tiene lugar ese viaje iniciático a Veruela por los mismos lugares que habría de recorrer el poeta sevillano.

Laura viaja en coche, en medio de una noche de tormenta dibujada con toda la sublimidad del prototípico paisaje gótico. El vehículo se detiene, porque algo le sobrecoge $\mathrm{y}$, sugestionada por la historia leída, cree ver sombras y sentir la presencia de seres, donde en apariencia solo habría un gato huidizo.

El plano siguiente recoge ya la huida de Casca, de semblante considerablemente más joven, viste de riguroso negro, con lo que parece algún tipo de amuleto al cuello y presenta el pelo suelto y enmarañado. Resulta relevante señalar que el paisaje que enmarca estas escenas iniciales, en clara oposición al anterior, se nutre de fuerte dosis de realismo, y no encuentra paralelismo alguno con el texto original: el sol ilumina un monte en el que ha desaparecido todo elemento que evoque el espacio sublime del gótico y apenas sí genera inquietud el enorme precipicio que separa a Casca de sus vecinos. El desasosiego experimentado por Laura al comienzo de la historia, se repetirá más adelante en el tránsito en medio de la oscuridad por los pasillos laberínticos del monasterio de Veruela. Se percibe este del exterior, pero se alimenta de aquellas emociones previas recreadas en la mente, evidenciando la operatividad del artificio elaborado de forma magistral por Bécquer. El terror externo forma parte ya del ideario del lector y afectará a sus 
comportamientos y a su interpretación del mundo. A partir de este plano, el discurso se desdobla parejo a la experimentación con una u otra emoción.

Pues el horror en el gesto de Casca obedece a la situación desesperada en la que se halla, presa de la persecución a la que la somete el pueblo, aquí representado no solo por hombres, sino incluso por mujeres. Se desvanece la inquietud y el desasosiego y, apenas pisa el escenario de los hechos, cede esta el protagonismo, al otro vértice del miedo, el horror. Las aportaciones de los historiadores amplían el perspectivismo del texto gracias a esta nueva voz, pues si una mujer caía acusada de brujería en manos de la Inquisición, podríamos decir que tenía suerte, porque iba a ser juzgada de manera más racional y más benéfica para ella que si caía en manos de sus convecinos.

Será esta la perspectiva que sitúa la ficción en la línea dibujada por Edgar Allan Poe y los primeros góticos, arriba comentada. El horror, procede en este caso de la ignorancia del pueblo y su exigencia última es revelar la maldad intrínseca al ser humano, decantándose en este momento por una otredad, mencionada por Bécquer en el texto, pero no trabajada en toda su hondura. Vuelve a primer plano la mirada de horror de Casca, que suplica piedad y jura no haber cometido delito alguno a unos aldeanos sumidos en el odio y con unas pretensiones de venganza absolutamente irracionales. En Veruela, Laura Contreras se encuentra con la realidad de un pueblo marcado por la huella de la superstición, anclado en tiempos ancestrales, que le impide aceptar la interpretación racional del mundo. El otro, que queda cerciorado y no solo intuido, es ahora uno mismo y el miedo es real y palmario.

El discurso da un giro y el horror parece invertir los términos previamente marcados, cuando Casca se arrodilla a rezar derivando el rezo en latín en una súplica satánica. La ficción se recrea en el poder dominador de la bruja, que ha adquirido aquí el papel de hechicera (Lara Alberola: 2018), dominadora absoluta de la propia naturaleza, siendo responsable incluso del movimiento de las nubes, de la formación de torbellinos en el cielo y de un eclipse solar, que se habría producido en 1860 y que habría desatado en el pueblo de Veruela el más absoluto caos. La configuración de la bruja, ahora en el marco de lo posible, se completa con las palabras del narrador final de la Carta VIII que, en voz en off, describe a aquella descendiente de la tía Casca mientras cocinaba lo que interpreta definitivamente como un guiso infernal, al acompañarse de imágenes de enorme plasticidad de vísceras de todo tipo cocinadas en una enorme olla vieja.

Sin embargo, el documental apunta, antes de finalizar, a otra voz, que es la que observa a la bruja y al propio Gustavo Adolfo Bécquer como un solo ente en la otredad. Esta voz aparece desdibujada por pertenecer a un mundo en claro declive, el de la cultura popular, que por aquellas décadas aún sobrevivía en las zonas más rurales y aisladas, esperando una figura como la del poeta, que dejara constancia de sus vivencias; pero sobre todo por desconocer su existencia real, la verdad de sus prácticas, la relación con el pueblo, en definitiva, por encarnar en sí misma, como él en su obra y en su vida, la ambigüedad y el misterio. 


\section{CONCLUSIONES}

Hemos constatado a lo largo del presente artículo que la historia de la Tía Casca que recupera el documental Bécquer y las brujas continúa ahondando en la pluriperspectiva como mecanismo narrativo de enorme versatilidad en la configuración estructural de la carta VI de la obra Desde mi celda, en tanto que lo analiza, lo amplifica, lo enriquece. La disparidad de voces que fija Bécquer desde el texto escrito, como hemos observado, impide fijar desde el texto una perspectiva como única, siendo todas ellas igual de posibles o improbables, en clara deuda con la corriente de la novela gótica y su conflicto racionalismo-irracionalidad, para dejar la responsabilidad en el lector, que, condicionado por las propias emociones que le ha generado el discurso, se decantará por una determinada postura ante una realidad que, proyectada la posibilidad de la duda, ya nunca volverá a ser la misma.

\section{REFERENCIAS BIBLIOGRÁFICAS}

AMORES, M. (1999). “¿Son poéticas las brujas? En torno a tres cartas Desde mi celda de Gustavo Adolfo Bécquer”. En Brujas demonios y fantasmas en la literatura fantástica hispánica, J. Pont (ed.), 191-203. Lleida: Universitat de Lleida.

Bruzos, A. (2005). "Análisis de la enunciación irónica: del tropo a la polifonía". Pragmalingüistica 13, 25-49.

BURKE, E. (2005). Indagación filosófica sobre el origen de nuestras ideas acerca de lo sublime y lo bello. Madrid: Alianza Editorial.

CARo Baroja, J. (1995 [1966]). Las brujas y su mundo. Madrid: Alianza.

Díez de Revenga, F. J. (2007-2008). "Brujas en Gustavo Adolfo Bécquer, Cartas desde mi celda". Estudios Románicos 16-17, 369-387.

Domínguez Lasierra, J. (1999). "Bécquer desde Veruela". Mar oceana: Revista del humanismo español e iberoamericano 3, 153-165.

Ducrot, O. (1984). El decir y lo dicho: polifonía de la enunciación. Barcelona: Paidós.

Estruch Tobella, J. (2020). Bécquer. Vida y época. Madrid: Cátedra.

FABra SOldeVILla, Fr. (1838). Filosofia de la Legislación Natural fundada en la Antropología o en el conocimiento de la naturaleza del hombre y de sus relaciones con los demás seres. Madrid: Imprenta del Colegio de Sordo-Mudos.

FERNÁNDEZ, P. (2018). "Construyendo a la lectora moderna: lecturas emocionales para nuevas comunidades interpretativas. La Galería fúnebre (1831) de Agustín Pérez Zaragoza”. En La cultura de las emociones y las emociones en la cultura española contemporánea (siglos XVIII-XXI), L. E. Delgado, P. Fernández y J. Labanyi (eds.), 75-98. Madrid: Cátedra.

FISHER, M. (2016). Lo raro y lo espeluznante. Barcelona: Alpha Decay.

HAMON, PH. (2007). Imageries. Littérature et images au XIX siècle. Paris: José Corti. 
Kanta, E. (1984). Lo bello y lo sublime: ensayo moral y estético. Madrid: Austral.

LARA AlBerola, E. (2019). "La brujería en la narrativa histórica española contemporánea (desde 1970 hasta la actualidad)". Revista de Humanidades 37, $35-72$.

LARra, M. J. (1984). “¿Quién es el público y dónde se encuentra?”. En Artículos, 127138. Madrid: Cátedra.

LóPEz SANTOS, M. (2010). La novela gótica en España (1788-1833). Vigo: Academia del Hispanismo.

(2020). Las llaves para el castillo. Claves interpretativas de la novela gótica. Berlín: Peter Lang.

PAlOMO, M. P. (1985). "El mito del Moncayo en la prosa becqueriana". Turia 1, 13-19.

RoAs, D. (2001). “La amenaza de lo fantástico". En Teorías de lo fantástico, D. Roas (ed.), 7-44. Madrid: Arco / Libros.

(2011). La sombra del cuervo. Edgar Allan Poe y la literatura fantástica española del siglo XIX. Madrid: Devenir Ensayo.

Rubio JimÉneZ, J. (2019). “Introducción”. En Desde mi celda, G. A. Bécquer, 9-133. Madrid: Cátedra.

SEBOLD, R. (1989). Bécquer en sus narraciones fantásticas. Madrid: Taurus.

SPRENGER, J. (2004 [1486]). Malleus Maleficarum. Valladolid: Maxtor.

ZAVALA, I. (1995). "Erotismo y terror; el fantasma del texto o cuando los espejos tienen manchas”. España Contemporánea: Revista de Literatura y Cultura 8.2, 117-128.

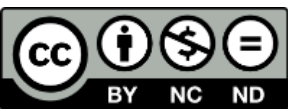

This work is licensed under a Creative Commons AttributionNonCommercial-NoDerivatives 4.0 International (CC BY-NC-ND).

Fecha de recepción: 02/02/2021

Fecha de aceptación: 14/05/2021 